\title{
Charles Baudelaire, Il vulcano malato. Lettere
}

1832-1866

\section{Maria Emanuela Raffi}

\section{Q OpenEdition \\ 1 Journals}

\section{Edizione digitale}

URL: http://journals.openedition.org/studifrancesi/9308

DOI: $10.4000 /$ studifrancesi.9308

ISSN: 2421-5856

\section{Editore}

Rosenberg \& Sellier

\section{Edizione cartacea}

Data di pubblicazione: 1 juin 2008

Paginazione: 216

ISSN: 0039-2944

\section{Notizia bibliografica digitale}

Maria Emanuela Raffi, «Charles Baudelaire, I/ vulcano malato. Lettere 1832-1866», Studi Francesi [Online], 154 (LII | I) | 2008, online dal 30 novembre 2015, consultato il 13 janvier 2021. URL: http:// journals.openedition.org/studifrancesi/9308 ; DOI: https://doi.org/10.4000/studifrancesi.9308

Questo documento è stato generato automaticamente il 13 janvier 2021.

\section{(c) (i) $\odot$}

Studi Francesi è distribuita con Licenza Creative Commons Attribuzione - Non commerciale - Non opere derivate 4.0 Internazionale. 


\title{
Charles Baudelaire, Il vulcano malato. Lettere 1832-1866
}

\author{
Maria Emanuela Raffi
}

\section{NOTIZIA}

CHARLES BAUDELAIRE, Il vulcano malato. Lettere 1832-1866, a cura di Cinzia BIGLIOSI FRANCK, Roma, Fazi Editore, 2007, pp. XXXIII+543.

1 La pubblicazione di una scelta di lettere di Baudelaire in traduzione italiana - in un solo volume e per di più con un titolo allusivamente accattivante - rappresenta certamente un contributo alla divulgazione di una più ampia conoscenza dell'autore delle Fleurs du mal. In questa ottica vanno iscritte anche la Nota biografica e il «Repertorio delle persone più citate nell'Epistolario» che accompagnano le lettere. Il saggio introduttivo della curatrice, La poesia e l'esilio. Intorno all'epistolario di Baudelaire, di taglio decisamente biografico, propone una lettura della visione baudelairiana fortemente ancorata alla definizione di 'homo duplex' data di sé dallo stesso poeta e dominata dall'idea che l'opera baudelairiana costituisca in qualche modo un riscatto immaginativo e poetico di un'esistenza fallimentare, di «una vita che più di tutto mancò a se stessa». 